TRAMES, 2009, 13(63/58), 4, 401-424

\title{
RULES FOR ESTONIAN SIGN LANGUAGE TRANSCRIPTION
}

\author{
Regina Paabo, Monika Födisch, and Liivi Hollman \\ Estonian Association of Sign Language Interpreters, Tallinn
}

\begin{abstract}
Estonian Sign Language (ESL) is the native language for approximately 1,500 Estonian Deaf people. Like other sign languages, ESL has no written form. In the history of ESL research, different transcription systems have been used. The system introduced here is the amended version of the transcription system first presented in 2006. The structure of the transcription system follows the example of W. Stokoe's notation system and its expansions. Phonemes of Estonian Sign Language are introduced and symbols for 36 hand forms, 27 locations, and 20 different movements are presented. All symbols are easy to use with any computer program. For the detailed transcription of the signs, symbols for the palm and finger orientation as well as the relationship between the two hands are given. The general algorithm proposed here for sign transcription follows the structure of HamNoSys, notating hand form first, followed by internal movement of the hand, palm and finger orientation, location and movement.
\end{abstract}

DOI: $10.3176 /$ tr.2009.4.05

Keywords: sign language, sign language transcription, Estonian Sign Language

\section{Rules for Estonian Sign Language transcription}

Estonian Sign Language (ESL) is the language of Estonian deaf community and it has currently approximately 1,500 primary users. ESL is described in Ethnologue under the Ethnologue Language Code eso (see also Sutrop 2000).

Since the first deaf school was established in Estonia in 1866, oral teaching method prevailed in education of the deaf in Estonia, as in many other countries, for more than a century. Despite that, ESL became an important communication tool for the students who spent most of their time in the boarding school and at times the use of ESL for student communication was even supported. The end of the 1980s brought along many social and political changes in Estonian society. Cultural self-awareness of the deaf community started to increase, the society became more open for different minority groups and deaf people had wider opportunities to study, work and actively participate in societal life. These changes 
also initiated ESL research in the end of the 1980s, and from the early 1990s ESL has been used as teaching language in deaf education. Today ESL is a developing language; it is taught in universities and in other schools as a second language and interpreting services from and into ESL are provided for its users. Since 2007 ESL is enacted by the Language Law, which defines ESL as a separate language and signed Estonian as a form of Estonian. The law also stipulates that the state encourages the use and development of ESL and signed Estonian. For the deaf people the right to use ESL or signed Estonian in communication is guaranteed by provision of sign language interpreting services.

During the last two decades, three small ESL dictionaries have been written (Toom 1988, 1990; Kivisild and Toom 1990); they contain approximately 700 signs that form the basic vocabulary of ESL. Some general overviews about sign languages and ESL have been published (Laiapea 2007). More specific descriptions have focused on noun phrases (Miljan 2000), adjectives (Miljan 2001), category of number (Miljan 2003) and expressing time relations in ESL (Trükmann 2006) as well as the classification and etymology of name signs (Paales 2002).

\section{ESL phonology research}

Studies on ESL phonology are based on William C. Stokoe's descriptions of the structure of signs. In his Sign Language Structure from 1960 Stokoe first showed that signs have parts as do words in spoken languages. These three aspects - (1) the place where a sign is made, (2) the distinctive hand configuration and (3) the action are combined simultaneously to form lexical units of a sign language and are therefore functioning similarly to the phonemes in a spoken language. Stokoe also presents the symbols for these parameters as well as formulas for ASL notation (Stokoe 1978; Valli \& Lucas 2000:243-246). The ESL transcription system introduced here is based on the Stokoe's system and its expansions.

The very first efforts to note down ESL signs were made in the beginning of the 1990s. At that time two parallel ESL research groups were working in Estonia. One of them was Sign Language Centre directed by Vahur Laiapea in Porkuni Deaf School (1991-1992) and the other one ESL research group directed by Regina Paabo (Toom) at the University of Tartu (1989-1990). Both groups described hand forms used in ESL and introduced different systems for noting them down. The research group of the University of Tartu described 36 ESL hand forms (Figure 1), 23 location phonemes and 29 movement phonemes.

As seen in Figure 1, the symbols except for the hand forms 7, 23, 24, 25 and 26, originate from Estonian manual alphabet and number system. A dot preceding the symbol marks the thumb moved away from the hand, three dots represent curved fingers, a circumflex $(\wedge)$ marks contact between the thumb and straight fingers, and a small circle contact between the thumb and curved fingers, a macron represents rectangular bent of fingers without contact with the thumb.

In sign analyses the orientation of the palm and fingers were also taken into consideration, as well as the relationship of both signing hands following three 
1

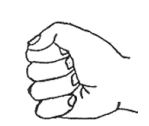

A

7

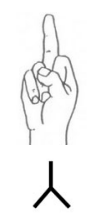

13

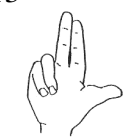

K

19

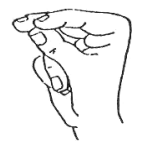

$\hat{3}$

25

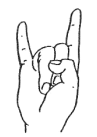

2

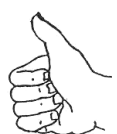

A

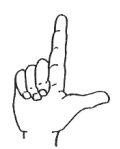

L

14
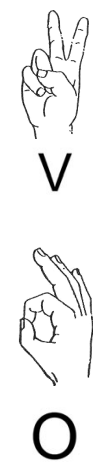

26
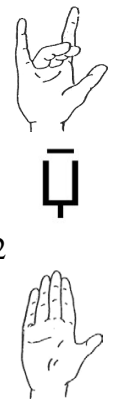

B
3

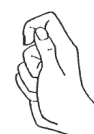

9

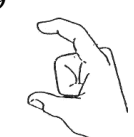

L̈

15
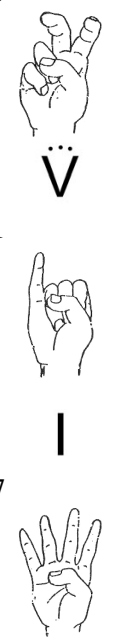

4

33

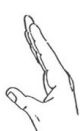

B
4

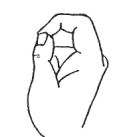

$\AA$

10

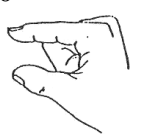

L

16
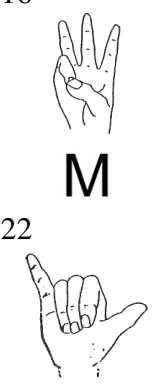

28

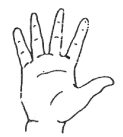

5

34

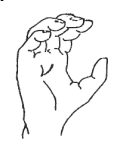

5

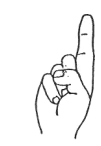

11

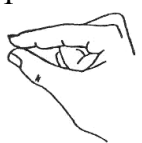

$\hat{L}$

17
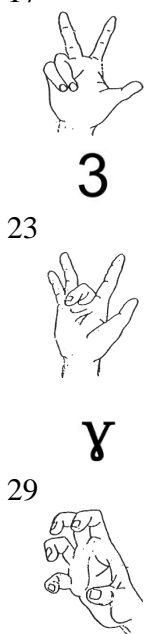

30

18

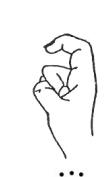

12

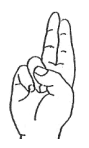

K

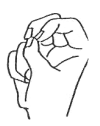

24

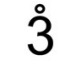<smiles>O=C1C=CC=CC1</smiles>

S

Figure 1. ESL hand forms presented by the ESL research group from the University of Tartu, 19891990

different formulas (one for one-handed signs, the second for two-handed signs, where both hands are active and the third for two-handed signs where one hand is passive). The notation system was developed based on the symbols introduced by Mary Brennan (Brennan 1990) and symbols marking the areas of signing space by Terhi Rissanen (Rissanen 1985:18). The system was however not widely spread, the symbols and formulas were only used by the research group itself and in teaching sign language at the University of Tartu. 
The Sign Language Centre of Porkuni Deaf School introduced 38 different ESL hand forms (Figure 2). Comparison of the figures shows that these two systems did not differ only in the number of hand forms. There were 29 hand-

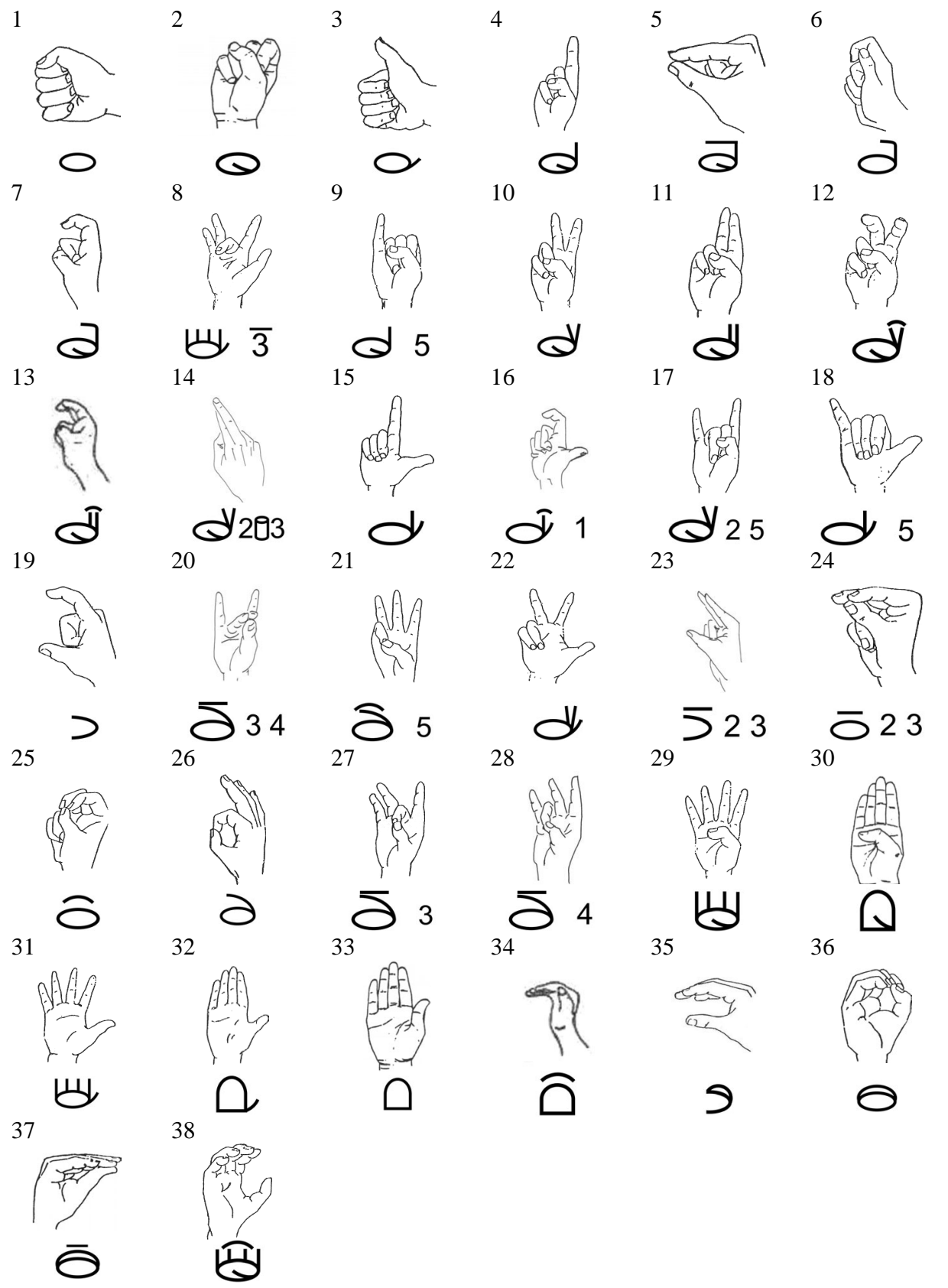

Figure 2. ESL hand forms presented by Sign Language Centre of Porkuni Deaf School, 1991-1992 
shapes common for both, but the research group at the University of Tartu had 7 additional hand forms in their descriptions (Figure 1, hand forms 4, 7, 10, 13, 26, 31 and 33) and Sign Language Centre in Porkuni described 9 additional handshapes (Figure 2, hand forms 2, 13, 14, 16, 20, 23, 28, 30 and 33). The symbols used in the latter system are the iconic representations of the fist or palm, the fingers are numbered and if needed the numbers are used to show which fingers are bent or straightened.

Most of the hand forms appearing only in one system could be considered as the varieties of the main hand form, not having the distinctive function in ESL itself (Figure 3).

The use of different variants is dependant on the co-articulation possibilities of the respective phoneme with other parameters of the sign. As an example, while sign SATURDAY (Figure 4c) is formed by A hand form (Figure 4a) to smooth the

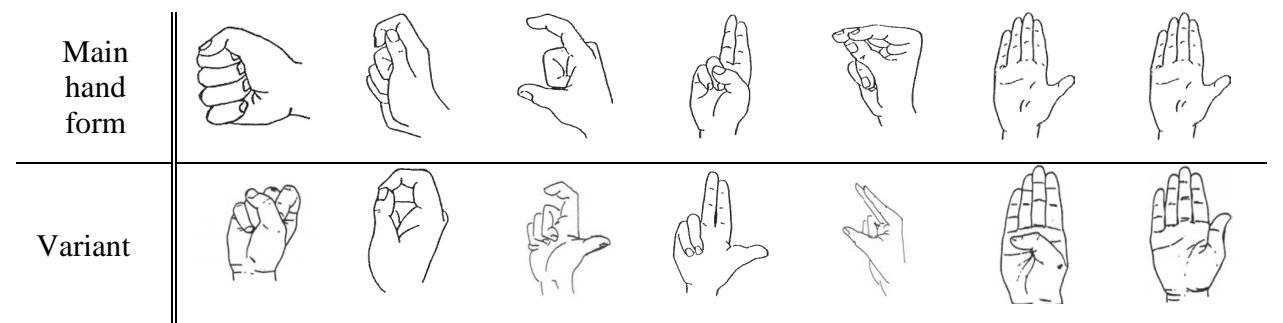

Figure 3. Some varieties of the main hand forms described by either of the research groups

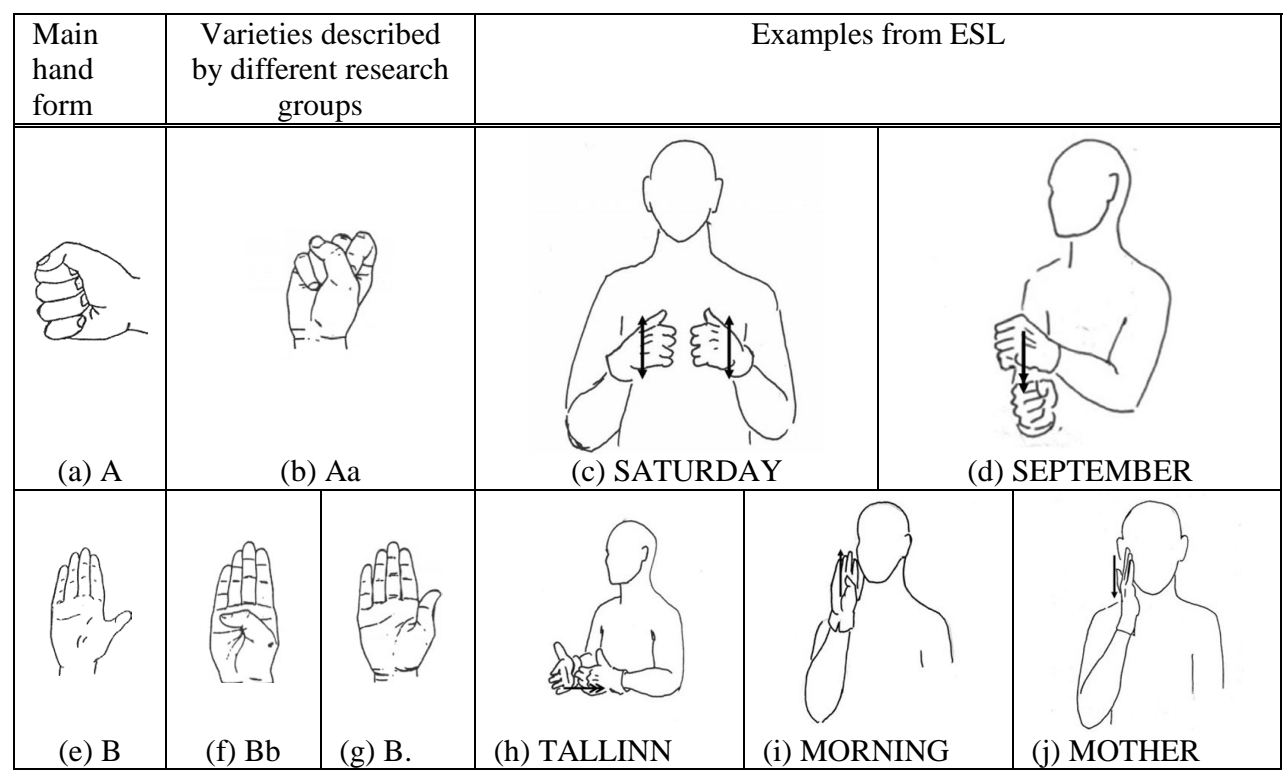

Figure 4. Some varieties of the main hand forms described by the research groups and the examples of their use 
movement along the body, sign SEPTEMBER (Figure 4d) in contrast is articulated with Aa (Figure 4b) variant to ease the contact between two hands articulating the sign. Similarly, while TALLINN (Figure 4h) may be articulated with either B or $\mathrm{Bb}$ hand-shape, formation of the sign MORNING (Figure 4i) by the movement along the cheek needs for Bb (Figure 4f) hand-shape. Sign MOTHER (Figure 4k) may thereat be articulated either by B or B. (Figure $4 \mathrm{~g}$ ) hand form without any change in its meaning.

The other examples of the differences in the above described systems include both productive ESL hand-shapes like $\mathrm{N}$ (Figure 2, hand form 28, Figure 5a) or $\mathrm{L}_{-}$ hand forms (Figure 1, hand form 10, Figure 5b) and hand-shapes disappearing from ESL (Figure 1, hand form 7) or used only in ESL fingerspelling alphabet (Figure 2, hand form 14, Figure 5c).

Further research about ESL phonology has introduced more changes into above mentioned systems. Analyses of 383 signs from an ESL dictionary (Toom 1988) show that these signs contain the total of 80 phonemes: 34 different hand forms, 19 locations and 27 movements (Püvi 2006:31). Although the number of signs in this study is too small to enable any definitive conclusions, it is however interesting to bring out some observations. Comparing the hand forms described by Püvi and the research groups from the University of Tartu and Porkuni Deaf School, it may be seen that from the 36 hand forms presented by the University of Tartu, 33 hand forms also exist in Püvi's analyses, 3 hand forms (Figure 1, hand forms 10, 13 and 31; hand forms 31 and 34 were described as varieties of the same form) are missing and there are 2 additional hand forms (Figure 7, hand forms $22-\mathrm{N}$ and $10 \mathrm{a}-\mathrm{K}$ :) that were not described by the research group of the University of Tartu.

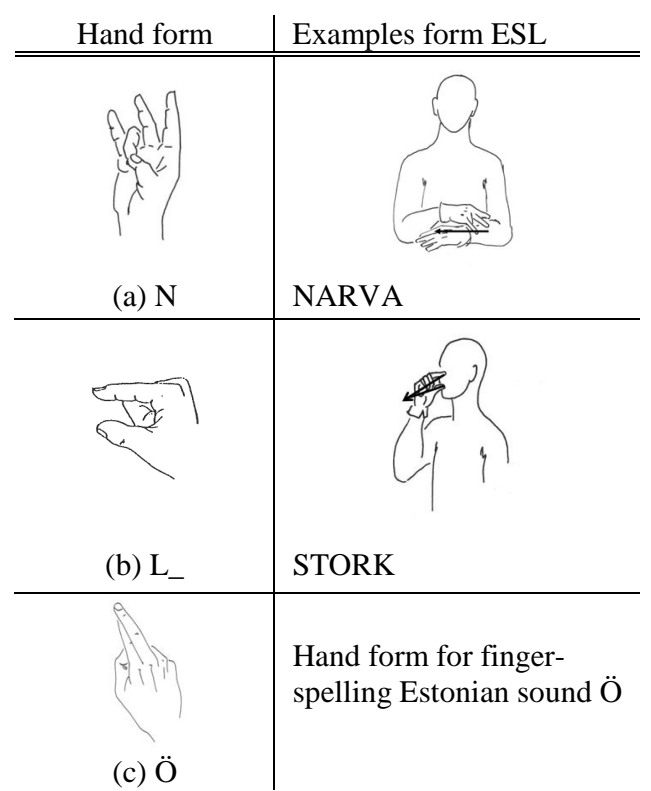

Figure 5. Some ESL hand forms described by different research groups and the examples of their use. 
The first was also described by the Sign Language Centre and mentioned above in Figure 5a, the other one is not listed in either of the described systems but obviously used only in one of the foreign loan signs (Figure 7, hand form 34, sign STATE, Figure 6b).

From the 38 hand forms presented by the Sign Language Centre of Porkuni Deaf School 31 exist in Püvi's analyses and 7 are not observed (Figure 2, hand forms 2, 13, 14, 16, 23, 30 and 33). Hand-shape 2 is considered as a variety of shape 1 according to Püvi and hand-shapes 30 and 33 as varieties of hand-shape 33. Additionally there are three hand forms that were not described by Sign Language Centre but exist in Püvi's description (Figure 7, 3a - Ao, 10a - K: and 30 - B_) (Püvi 2006: 31). Hand form 20 has slightly different form in Püvi's description - in the first it is described with closed thumb and middle fingers, in the latter with open fingers.

Therefore, adding to the above-mentioned systems one hand form, Püvi excludes the hand-shapes disappearing from ESL or used only in ESL fingerspelling alphabet, and the varieties shown in Figure 3. Some of the varieties are observed but defined as variants of the main form.

According to Püvi (Püvi 2006:26, 28) the most productive location in ESL sign formation is neutral space, where $47 \%$ of all the studied signs are articulated. Nondominant hand (26\% of studied signs) - upper arm, forearm, elbow, palm and back of the arm and different parts of the head (18\% of studied signs) - face, forehead, temple, eyes, nose, cheek, ear, lips, chin and neck, and body (9\% of studied signs) - chest, waistline and thigh, follow. There are 27 different movements, the most common of them vertical linear movements.

\section{ESL transcription system}

In relation to further ESL research at the University of Tartu and the Institute of the Estonian Language in 2005, a new need emerged to go through the existing transcription systems and adjust them for the use with different computer programs. The current paper is not an attempt to define the phonological structure of ESL but to give a hypothetical set of ESL phonemes based on earlier research and descriptions. The system presented here was first introduced in 2006 (Toom, Trükmann, Hollman 2006) and is now revised after being in use for some years. The system is mainly based on the studies of the sign language research group of the University of Tartu. The symbols for different phonemes originate from the Estonian fingerspelling alphabet and number system and were chosen so that they could be easily used with any computer program and easy to find on any keyboard. The suggested font for transcription is Arial, but the system is unambiguously comprehensible also in Times New Roman.

The symbols in the current ESL transcription system are generally based on Stokoe's notation system and its expansions; the formula for sign transcription follows mainly the structure of HamNoSys. The glossing rules presented here are based on the rules described by R. Sutton-Spence and B. Woll (2003). 
Drawn from an earlier research, a set of 36 hand forms is presented (Figure 7). As there is no analysis on the productivity of different hand-shapes in ESL, it has to be stressed again that the selection of hand forms presented here is only hypothetical. Hand forms which do appear in ESL but which distinctive function in the meaning of the sign is not verified, are shown as the varieties of the main forms. Variety of the hand-shape $10(\mathrm{~K}$.) appears only in one ESL sign (TULISTAMA SHOOT, Figure 6a) and therefore it may be assumed that, although described in one of the earlier systems, it is now disappearing from ESL.

The other hand-shape used in only one sign is hand form 34 (K:), appearing in RIIK - STATE (Figure 6b), which is in all probability a loan sign from Russian Sign Language (Russian Sign Language, Б hand form, used to articulate Russian sign for czar, emperor, czarist- (Marinina 2004:285).

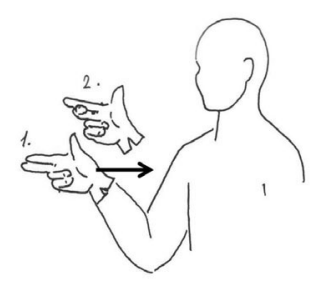

(a) SHOOT

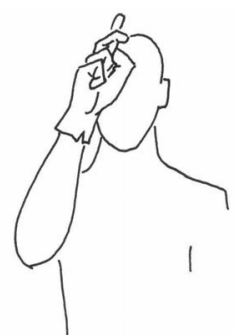

(b) STATE

$\mathrm{K}:) 1 \wedge 2 \mathrm{O}-$

Figure 6. ESL signs SHOOT and STATE, formed with hand-shape K. and K: (Illustrated by Jüri Laumets)

Analogically to Stokoe's notation system, the symbols of the hand forms are originated from Estonian fingerspelling alphabet and number system. A dot (.) after the symbols represents the thumb moved away from the hand, a dot (.) before the symbols represents the thumb moved close to the hand, a colon (:) represents curved fingers, lowercase $o$ (o) shows contact between curved thumb and fingers, circumflex $(\wedge)$ contact between straight thumb and fingers, and a dash $\left(\_\right)$ rectangular bent of fingers without contact with the thumb.

Internal movement of the hand is marked together with the hand form: asterisk $\left.{ }^{*}\right)$ after the symbol of the hand form represents wiggling of the fingers, a wavy dash $(\sim)$ warping of the fingers (e.g. formation of hand form $\mathrm{J}$ : from initial hand form $\mathrm{J}$ or formation of $\mathrm{V}$ : from initial hand form $\mathrm{V}$ ), an hash mark (\#) represents bending of straight fingers into contact with the thumb (e.g. formation of hand form $\mathrm{D}$ from initial hand form $\mathrm{B}$ or $\mathrm{B} \_$) and a capitalized $u(\mathrm{U})$ opening of the hand (e.g. formation of hand form 5 from initial hand form E), a wavy dash together with hash mark ( \#) shows warping of the fingers and closing the hand (e.g. formation of $\mathrm{A}$ hand-shape from 5 hand-shape). 


\begin{tabular}{|c|c|c|c|c|c|c|}
\hline No & \multicolumn{2}{|c|}{ Main hand form } & \multicolumn{4}{|c|}{ Varieties } \\
\hline & Hand form & Symbol & Hand form & Symbol & Hand form & Symbol \\
\hline & & $\mathbf{A}$ & & Aa & & \\
\hline & & A. & & $A:$ & & \\
\hline & & $\mathbf{A}^{\wedge}$ & & Ao & & \\
\hline & & $J$ & & & & \\
\hline & & J: & & & & \\
\hline & & $\mathbf{L}$ & & & & \\
\hline & & L: & & L.: & & \\
\hline & & L & & & & \\
\hline & 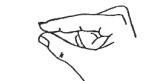 & $\mathbf{L}^{\wedge}$ & & & & \\
\hline & & K & $\mathrm{sit}$ & K. & & \\
\hline & & V & & & & \\
\hline 12. & & V: & & & & \\
\hline 13. & & M & & & & \\
\hline
\end{tabular}




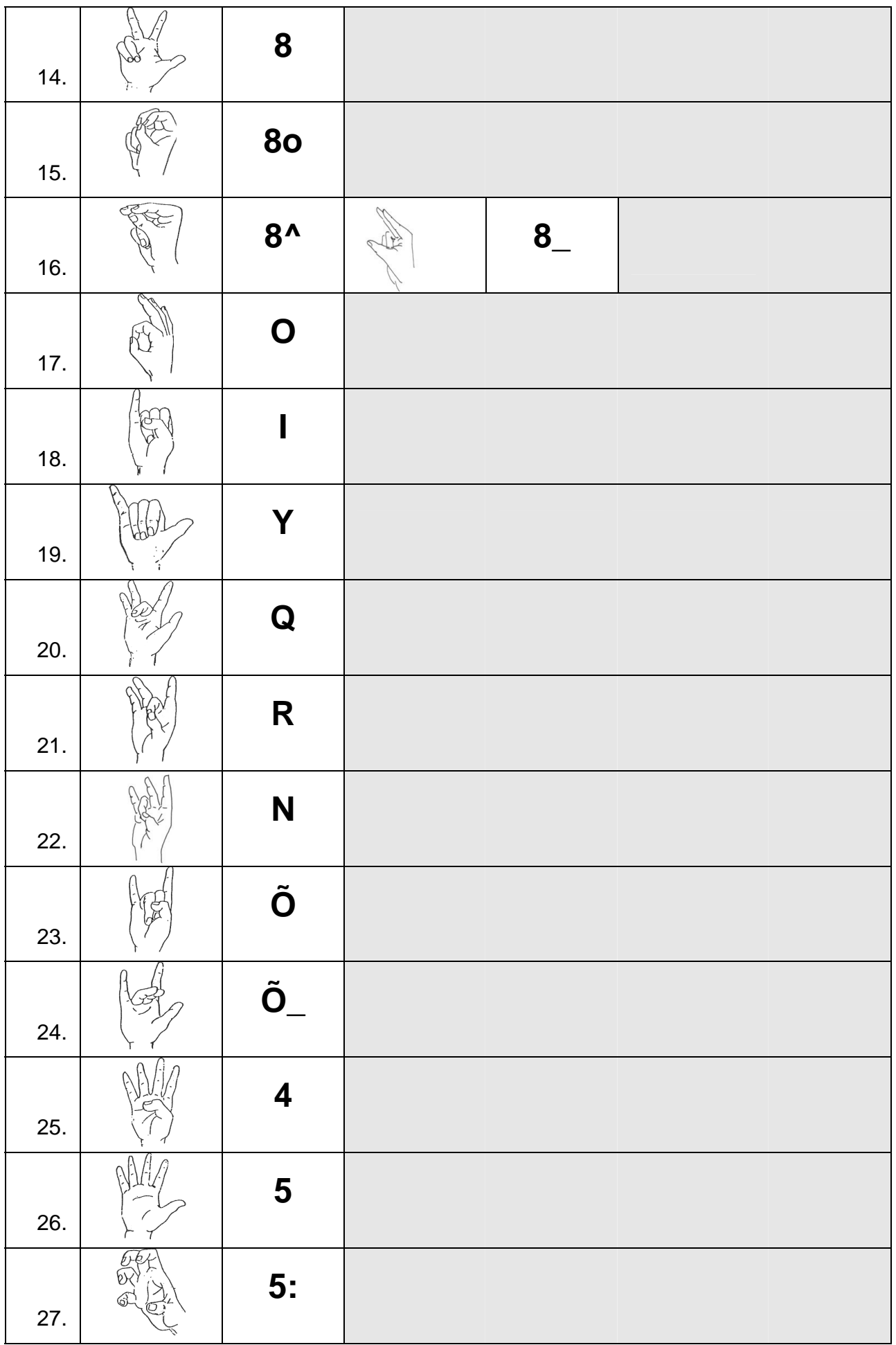




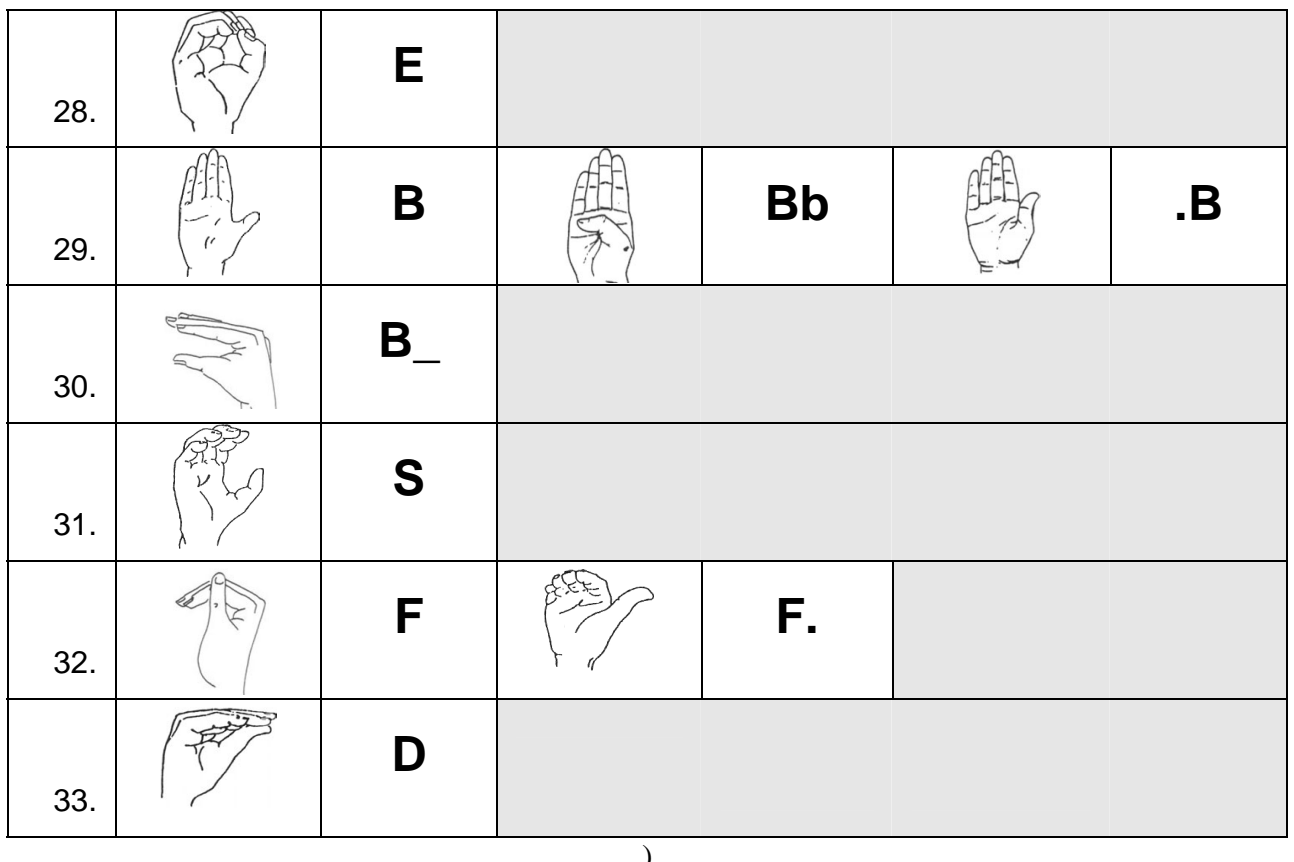

\begin{tabular}{|c|c|c|}
\hline & \multicolumn{2}{|c|}{ Foreign and rarely used hand forms } \\
\hline No & Hand form & Symbol \\
\hline 34. & 列 & K: \\
\hline 35 & & Ö \\
\hline 36. & & $\tilde{0}^{\wedge}$ \\
\hline
\end{tabular}

Figure 7. ESL hand forms and their symbols (illustrated by Jüri Laumets)

Orientation of the palm and fingers as an independent parameter of a sign is described already by Stokoe. In the current system it is recommended to note the orientation of the palm and fingers after the hand form using the symbols shown in Table 1.

On the third place in the transcription formula the location where the sign is formed, is notated. The current system allows notating of 27 different locations shown in Table 2. 
Table 1. Orientation of the palm and fingers

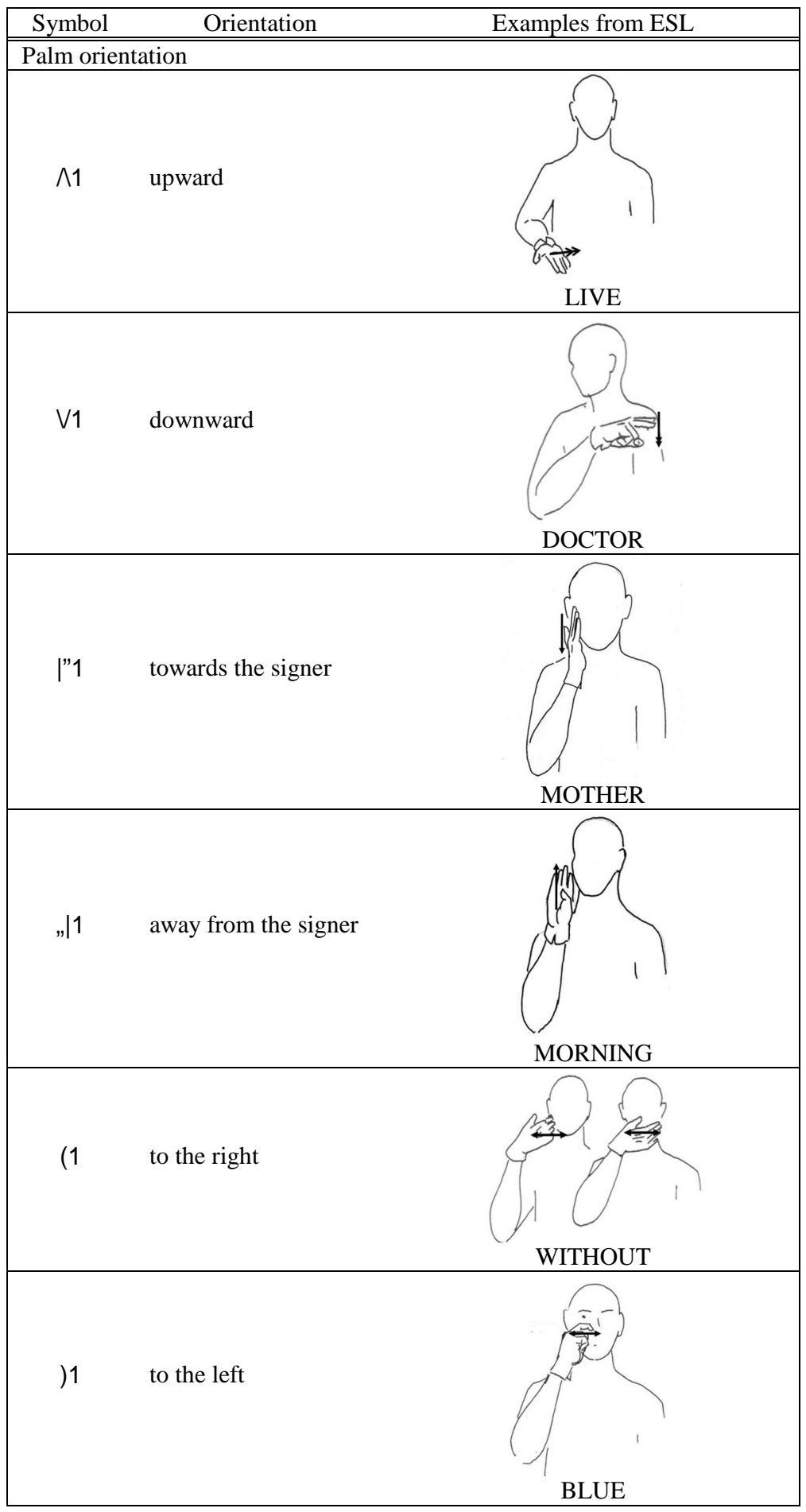




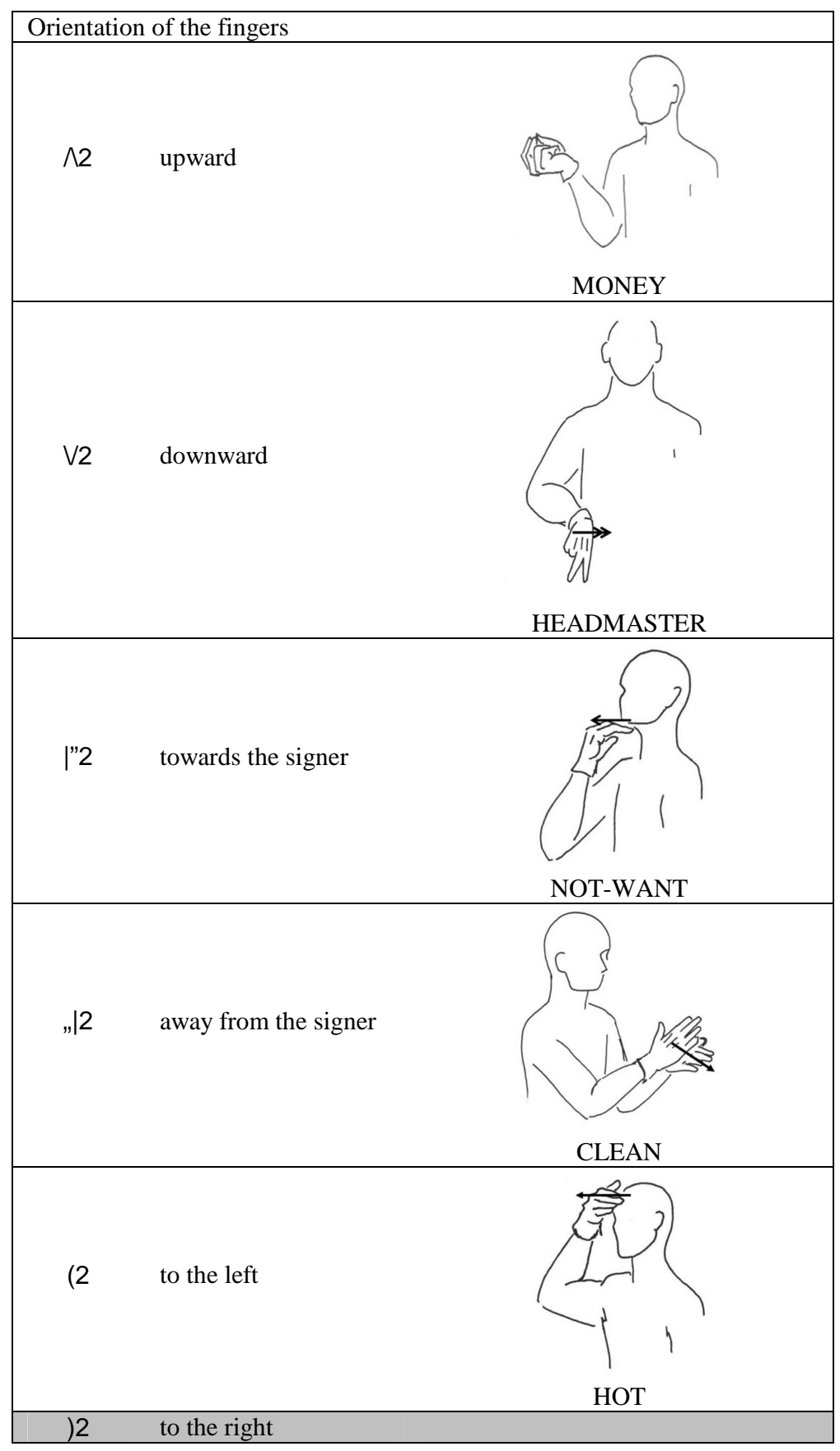


Table 2. Symbols for location phonemes

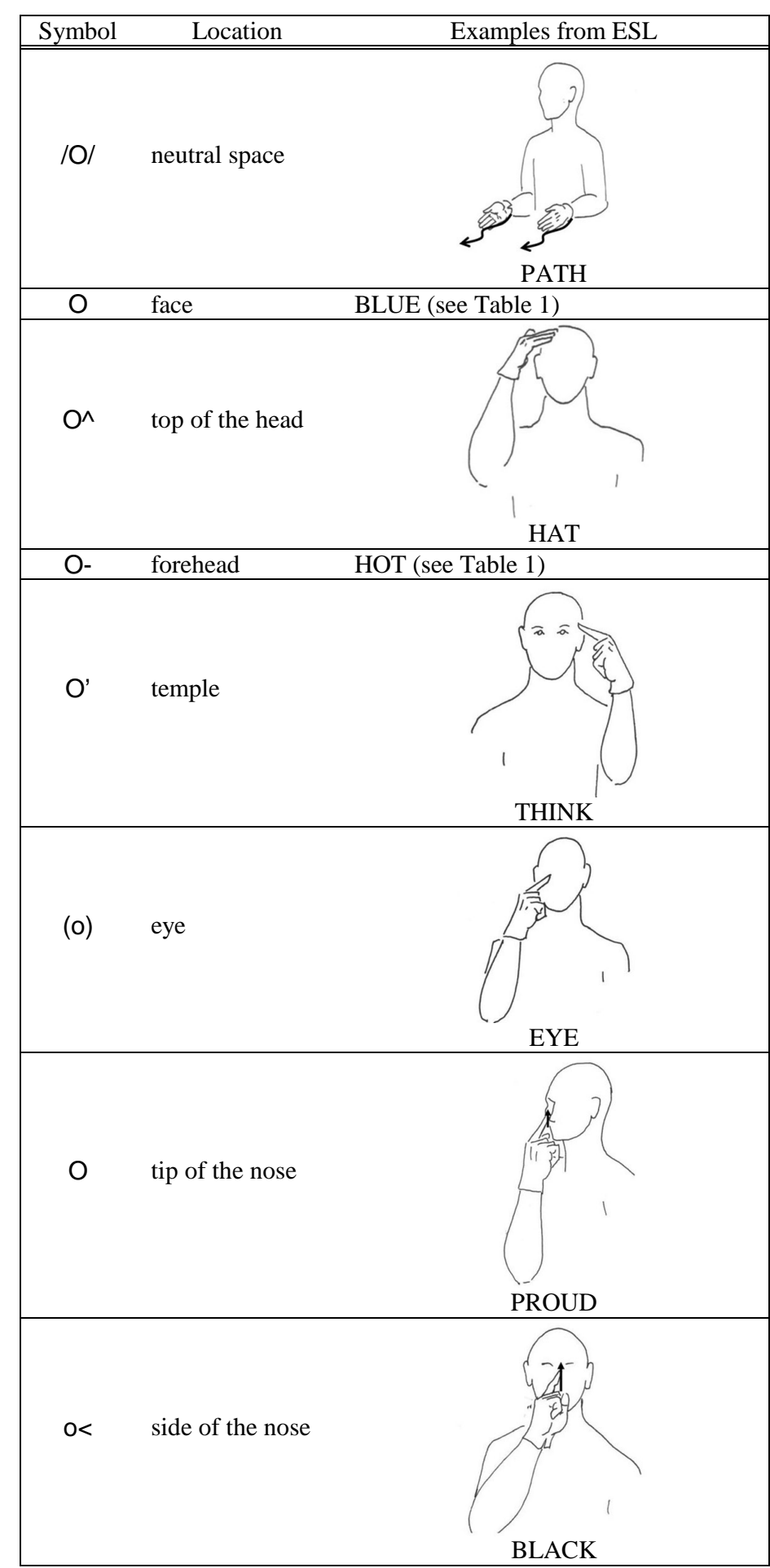




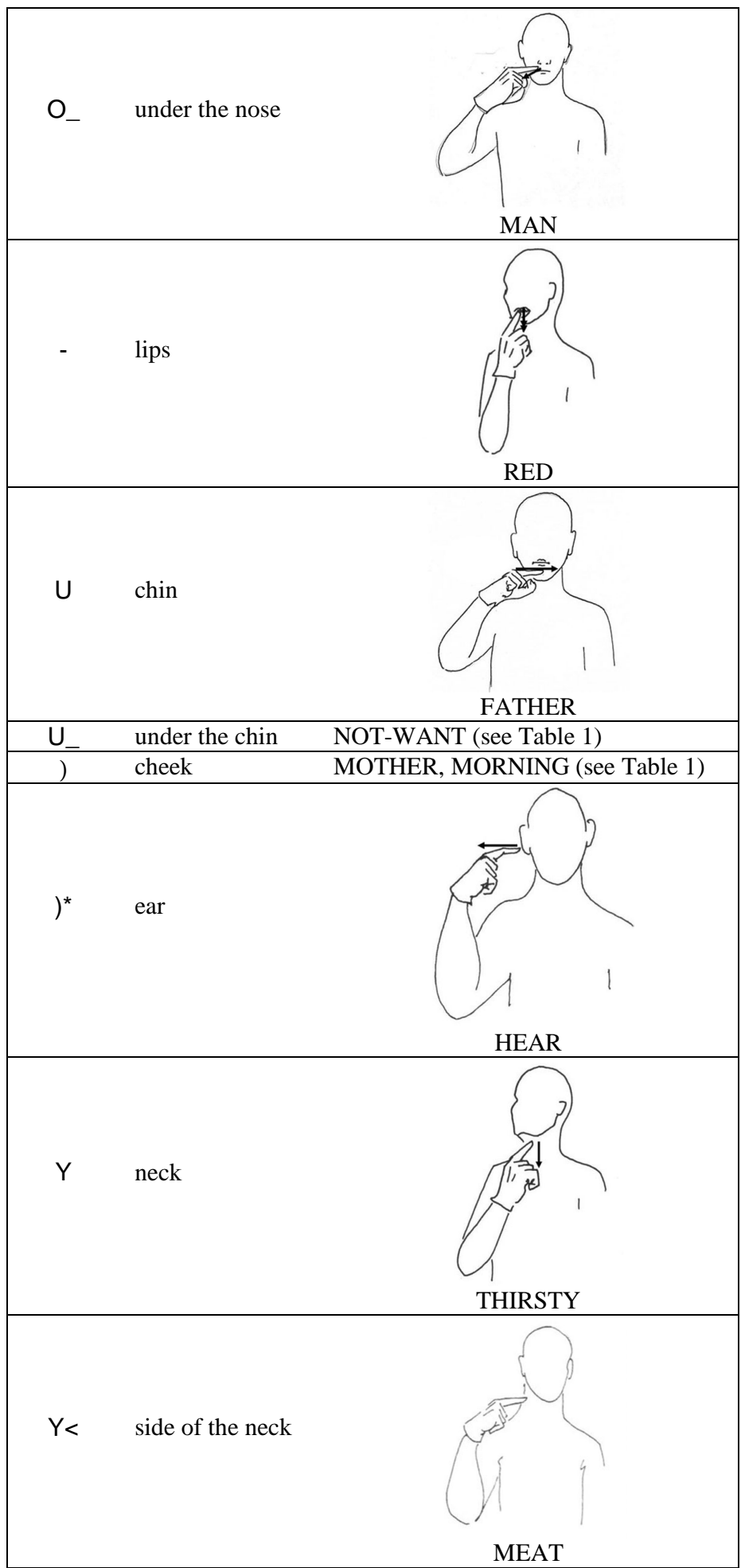




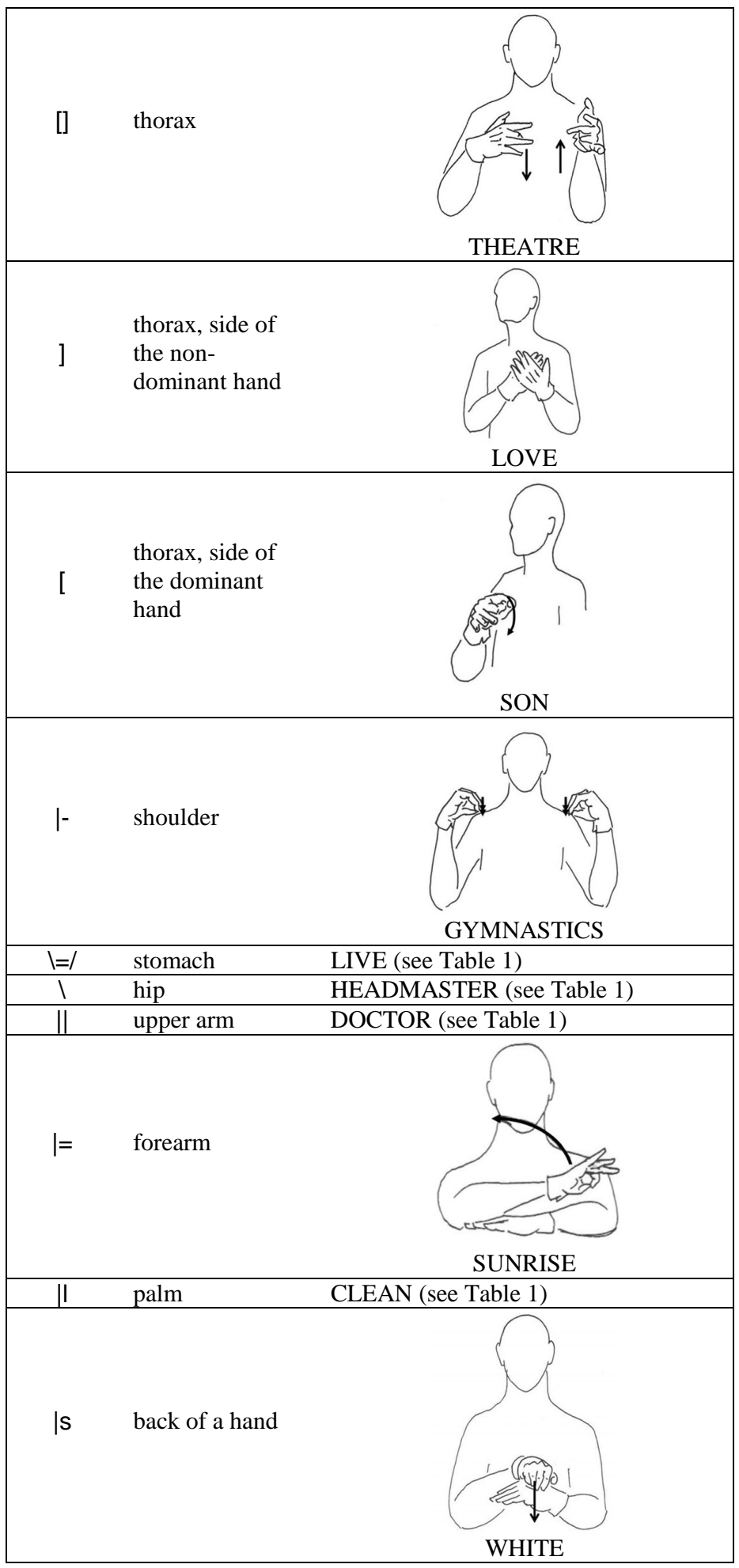




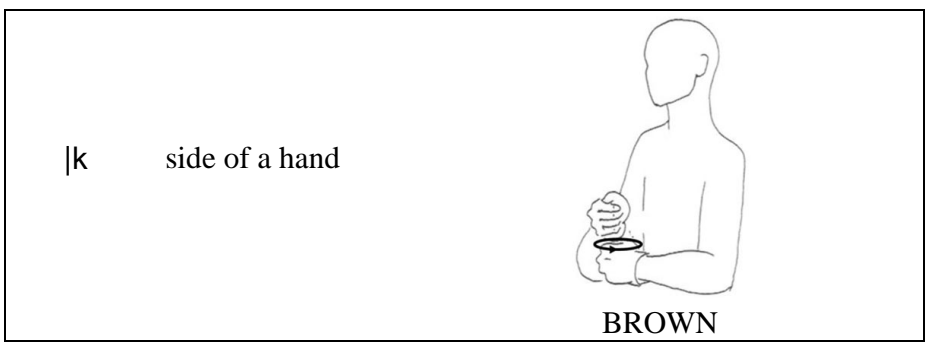

Symbols for movements are shown in Table 3. As mentioned above, internal movements of the hand during the sign formation are recommended to mark together with hand form (e.g. $5^{*}$ or $\mathrm{B}^{*}$ in case of GREEN or PINK; $\mathrm{J} \sim$ in case of HUNDRED). In the current system, similar symbols are used for the movement of fingers as well as the whole hand, so the placement of the symbol in the notation formula is very important (sign GREEN is formed with 5 hand form, wiggling fingers and an arced downward movement, sign PINK is formed by B hand, wiggling fingers and upward movement, sign DAY with closing 5 hand and downward movement) (Figure 8).

Table 3. Symbols for movement phonemes

\begin{tabular}{|c|c|c|}
\hline Symbol & Movement & Examples form ESL \\
\hline$\Lambda$ & upward & MORNING (see Table 1), BLACK (see Table 2) \\
\hline $\mathrm{V}$ & downward & MOTHER (see Table 1), THISRTY, SON (see Table 2) \\
\hline \multirow[t]{2}{*}{$\mathrm{N}$} & up and down & \\
\hline & & $\begin{array}{c}\text { SATURDAY } \\
\end{array}$ \\
\hline$>$ & towards the dominant hand & CLEAN (see Table 1), MAN, HEAR (see Table 2) \\
\hline$<$ & towards non-dominant hand & FATHER (see Table 2) \\
\hline \multirow[t]{2}{*}{$><$} & from sides to the centre & \\
\hline & & NIGHT \\
\hline Z & from side to side & WITHOUT, BLUE (see Table 1) \\
\hline$->$ & towards the signer & LIVE, HEADMASTER (see Table 1) \\
\hline$<-$ & away from the signer & NOT-WANT (see Table 1), WHITE, PATH (see Table 2) \\
\hline$-><-$ & $\begin{array}{l}\text { towards and away from } \\
\text { signer }\end{array}$ & THEATRE (see Table 2) \\
\hline
\end{tabular}




\begin{tabular}{|c|c|c|}
\hline W & turning from wrist & CONCERN \\
\hline$\%$ & disjoint & DIFFERENT \\
\hline$\sim$ & alternating & THEATRE (see Table 2) \\
\hline $\mathrm{X}$ & contact & THINK, EYE (see Table 2) \\
\hline C & round & RED \\
\hline$/: 1$ & rubbing & MONEY (see Table 1) \\
\hline $\mathrm{D}$ & arced movement & SON (see Table 2), NIGHT (see Table 3) \\
\hline$S$ & sinuous movement & $\begin{array}{l}\text { NATURE } \\
\text { NAT }\end{array}$ \\
\hline $\begin{array}{l}+ \\
+.- \\
\end{array}$ & $\begin{array}{l}\text { repeated movement } \\
\text { interrupted movement }\end{array}$ & $\begin{array}{l}\text { DOCTOR, HEADMASTER (see Table 1), } \\
\text { GYMNASTICS (see Table 2) } \\
\text { RAIN (Figure 6) }\end{array}$ \\
\hline
\end{tabular}

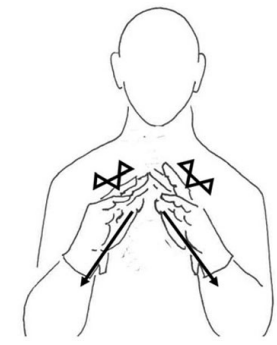

GREEN $5^{*}|| 5^{\star ”} \mid 2 / \mathrm{O} / \mathrm{\%} \%$

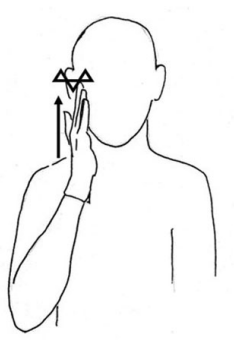

PINK

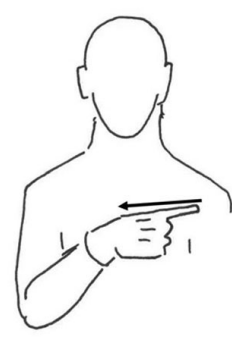

HUNDRED J |"1(2/O/>

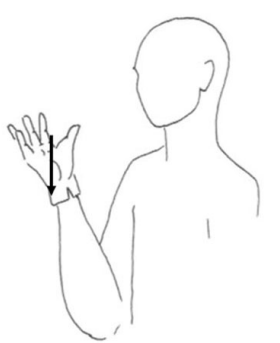

DAY 5\#|"1/2/O/V[D]

Figure 8. ESL examples of internal hand movement 
In case of two-handed signs it is suggested to mark the relationship of both signing hands, although it is not considered as an independent phoneme (Table 4). If the location of the sign formation is a passive hand, the relationship of the hands is not shown separately as the symbol of the location describes it already.

The symbols described above are used according to certain rules and principles. Transcribing a sign, the hand-shape together with the internal movement of the hand, as well as palm and finger orientation, is shown in the first place, and then

Table 4. Relationship of two signing hands in two-handed signs

\begin{tabular}{|c|c|c|}
\hline Symbol & Relationship of hands & LIVE (see Table 1), THEATRE (see \\
Table 2), GREEN (Figure 5)
\end{tabular}


location and movement follow. If the hand form or location changes during the sign formation, final hand form as well as final location are shown in square brackets [].

(1) Different symbols are notated in the following order: hand form, palm orientation, orientation of the fingers, location, movement, [final hand form, final location].

(2) In case of two-handed signs, hand form and location of the dominant hand are shown first, preceding the symbol of relationship of the hand and then the parameters of the passive hand.

(3) If the relationship of hands is not shown in case of two-handed signs, the location of the sign is the passive hand which is shown after the active hand. In case of manual location the movement marks the movement of the dominant hand.

If the formation of a sign consists of a combination of two or more movements (e.g. TOMORROW - arched movement away from the signer; RAIN interrupted downward movement, see Figure 9) all the movements are notated, whereby the order of the symbols is not relevant as far as the movements are simultaneous.

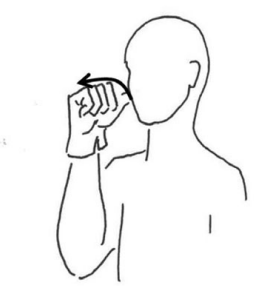

(a) TOMORROW Ä)1) $D<-$

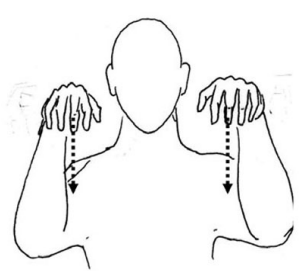

(b) RAIN 5:||5:V1/O/V-.-

Figure 9. Some examples of two simultaneous movements (Illustrated by Jüri Laumets)

\section{Some glossing rules adapted for glossing ESL}

Below are some glossing rules for describing ESL semantics and grammatical structure. The principles here are based on rules described by Sutton-Spence and Woll (2003), and are adapted to ESL and Estonian.

(1) To mark the meaning of a sign an Estonian counterpart is written in capital letters in its base form (MAGAMA - SLEEP).

(2) If it is not possible to find a single word to represent the meaning of a sign, low line is used (EI_TAHA - NOT_WANT). The same principle is adopted to mark head movement or facial expression accompanying the sign.

(3) Non-manual markers may be shown after the glossed sign while the line under it shows, when during the sign formation a certain head movement or facial expression emerges (DREAM squint eyes).

(4) In case of reduplication of a verb, two different glossing possibilities are used, either the meaning of the reduplicated verb is expressed (e.g. 
WAIT_FOR_LONG_TIME) or, if the reduplication itself has to be stressed, plus signs are used (WAIT +++).

(5) Fingerspelled words are written in lowercase letters, using hyphens: k-o-e-r $(d-o-g)$.

(6) To notate indexing, two strategies are used:

- only the meaning of the pointing is glossed according to the rules described above (YOU LOVE HIM/HER);

- indexing is glossed using the word osutus (pointing) and the certain area of the signing space is marked using the numbers for different signing space areas according to T. Rissanen (Figure 10). If it needs to be stressed that the pointing refers to first, second or third person, respective subscript is used - index $\left.x_{1,2,3}(\text { LOVE index })_{2}\right)$.

(7) Pauses between the clauses are marked by double slash (//).

(8) Classifiers are marked by abbreviation KLA. If needed, a classifier representing a person may be distinguished by the abbreviation in-KLA. Proform is marked by abbreviation PRO.

(9) Lexicalized fingerspelled signs, very rare in ESL, are marked by hash mark (\#) before the glossed sign.

Different line and arrow types used to mark sign formation in the pictures are based on the rules used in the first ESL dictionary (Toom 1988) and conventions used by Sutton-Spence and Woll (2003). Neutral movement is marked by regular lines, interrupted and slow movements by dotted lines showed in Figure 11. For repeated movements double arrows are used.

The colour of the arrow or line does not carry any meaning. In case of dark background, white lines and arrows may be easily used. Combining the line types and arrow's movements of different characters can be marked (Figure 12).

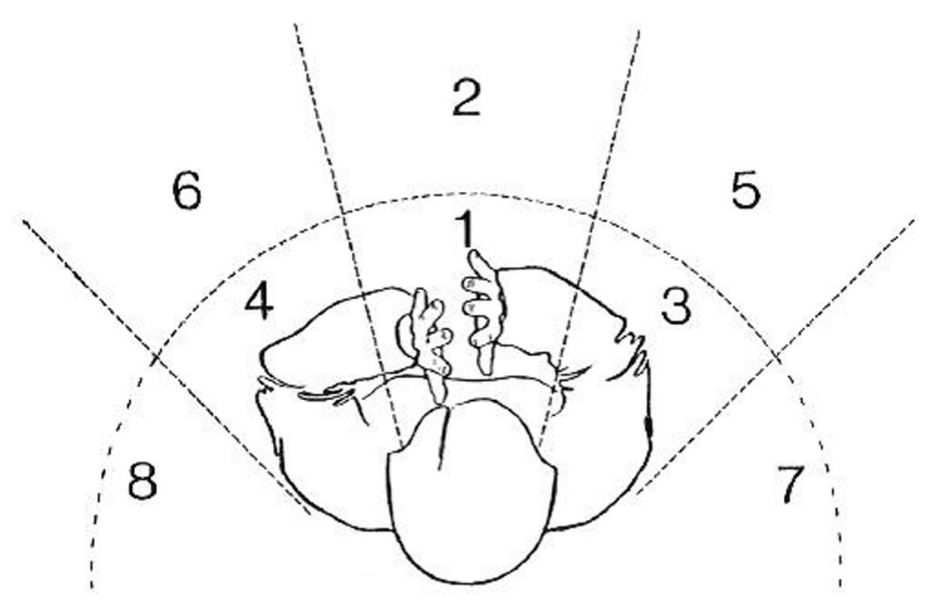

Figure 10. Areas of signing space by T.Rissanen 
marks neutral movement towards the arrow
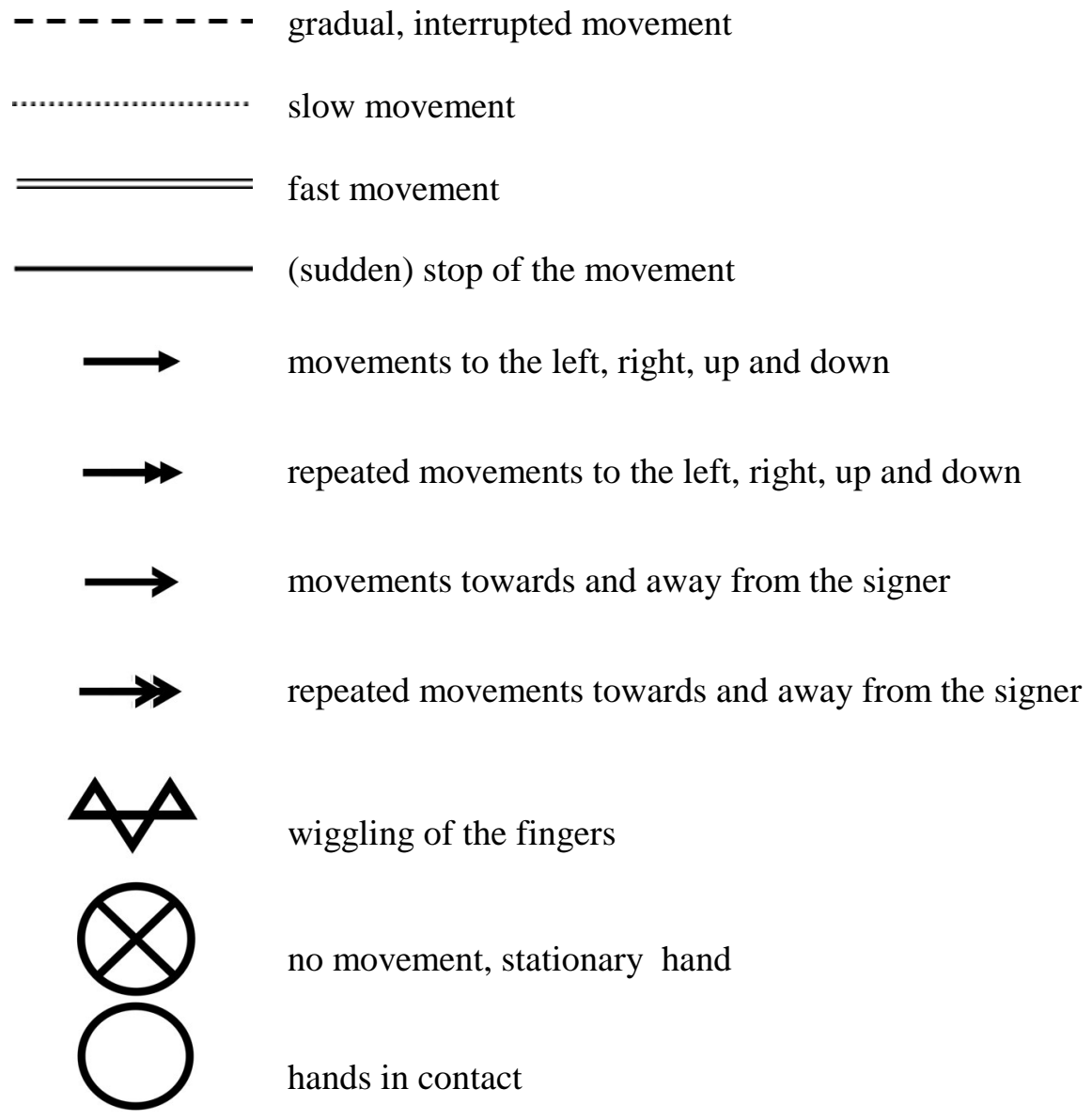

Figure 11. Line types for marking sign formation on the pictures<smiles>CC[C][14CH2][CH][14CH2]C</smiles>

slow up and down zigzag from left to right

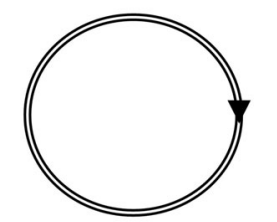

quick round movement

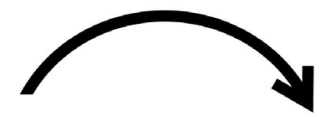

neutral arched movement away from the signer

Figure 12. Some examples of marking movements using the line types 


\section{Summary}

During the last two decades different transcription systems have been used in ESL research. The system introduced in the current paper is based on earlier research and descriptions of ESL phonology and comprises symbols for 36 ESL hand forms, 27 locations and 20 movements. The symbols originate from the Estonian fingerspelling alphabet and number system and have all been chosen so that they could be easily used with any computer program and from any keyboard. Sign transcription follows the formula where hand-shape together with the internal movement of the hand as well as palm and finger orientation is shown in the first place before location and movement. For notating ESL semantics and grammatical structure, some glossing rules are adopted. Marking sign movements on photos and drawings, line and arrow types and other symbols are presented.

Addresses:

Regina Paabo

E-mail: regina.paabo@ut.ee

Monika Födisch

E-Mail: monika.foedisch@yahoo.de

Liivi Hollman

E-mail: liivi@evkty.ee

Tel.: +372 5147822

Estonian Association of Sign Language Interpreters

Nõmme tee 2

13426 Tallinn, Estonia

\section{References}

Brennan, Mary (1990) Word formation in BSL. Stockholm: University of Stockholm.

Kivisild, Kai and Regina Toom (1990) Eesti kristlikud viiped. [Estonian Christian signs.] Tartu and Stockholm.

Laiapea, Vahur (2007) Keel on lahti. Tähendusi viipekeelest. [Estonian Sign Language: language, deaf children and the Deaf identity]. Tallinn: Eesti Keele Sihtasutus.

Marinina, R.G. (2004) Kniga žestov dlja neslysaslih ljudei. [Book of signs for Deaf people]. Donetsk: Stalker.

Miljan, Merilin (2000) The noun phrase in Estonian Sign Language from the typological perspective. Manuscript. BA Thesis. Tallinn: Estonian Institute of Humanities.

Miljan, Merilin (2001) "Adjectival modification in Estonian and Estonian Sign Language". In Estonian Typological Studies V, 169-188. (Publications of the Department of Estonian of the University of Tartu, 18.) Tartu.

Miljan, Merilin (2003) "Number in Estonian Sign Language". Trames 7, 3, 293-223.

Paales, Liina (2002) "Isiku- ja kohanimed eesti kurtide märgipärimuses". [Name signs for persons and places in Estonian Deaf folklore] Lemmeleht, 154-167. (Pro Folkloristika, 9.) Tartu: Eesti Kirjandusmuusum.

Püvi, Egle (2006) Eesti viipekeele keroloogiasüsteemi kirjeldus. [Description of Estonian Sign Language chereology]. Manuscript. BA Thesis. University of Tartu.

Rissanen, Terhi (1985) Viittomakielen perusrakenne. [The basic structure of sign language] (Publica- 
tions of University of Helsinki. Department of General Linguistics, 12.) Helsinki: Helsingin yliopisto.

Stokoe, William C. (1960) Sign language structure: a outline of the visual communication systems of the American Deaf. Silver Spring, MD: Linstok Press. (Revised ed. 1978.)

Stokoe, William C., Dorothy C. Casterline, and Carl G. Croneberg (2000) "Introduction to a dictionary of American Sign Language”. In Linguistics of American Sign Language, 243258. Clayton Valli and Ceil Lucas, eds. Washington D.C.: Gallaudet University Press.

Sutrop, Urmas (2000) Estonian Sign Language. In Ethnologue. Vol. 1. Languages of the world, 663. 14th ed. Barbara F. Grimes, ed. Dallas, Texas: Summer Institute of Linguistics.

Sutton-Spence, Rachel and Benice Woll (2003) The linguistics of British Sign Language: an introduction. Cambridge University Press.

Toom, Regina (1988) Kõnelevad käed. Eesti viipekeele sõnaraamat. [Talking hands. Estonian Sign Language dictionary.] Tartu: University of Tartu and Estonian Association of the Deaf.

Toom, Regina (1990) Abimaterjale eesti viipekeele omandamiseks. [Guidelines for learners of Estonian Sign Language.] Tartu: University of Tartu and Estonian Association of the Deaf.

Toom, Regina, Monika Trükmann, and Liivi Hollman (2006) "Eesti viipekeele transkriptsioonist". [On the Estonian Sign Language transcription]. Eesti Rakenduslingvistika Ühingu aastaraamat (Tallinn) 2, 285-301.

Trükmann, Monika (2006) Ajasuhete väljendamine eesti viipekeeles. [Temporal Relations in Estonian Sign Language.]. Manuscript. MA Thesis. Tartu: University of Tartu.

Valli, Clayton and Lucas Ceil (2000) Linguistics of American Sign Language: an introduction. Washington D.C.: Gallaudet University Press. 